\title{
Nuclear Thermal Rocket - Arc Jet Integrated System Model
}

\author{
Brian D. Taylor ${ }^{1}$ and William Emrich ${ }^{2}$ \\ NASA Marshall Space Flight Center, Huntsville, AL, 35812
}

\begin{abstract}
In the post-shuttle era, space exploration is moving into a new regime. Commercial space flight is in development and is planned to take on much of the low earth orbit space flight missions. With the development of a heavy lift launch vehicle, the Space Launch, System, NASA has become focused on deep space exploration. Exploration into deep space has traditionally been done with robotic probes. More ambitious missions such as manned missions to asteroids and Mars will require significant technology development. Propulsion system performance is tied to the achievability of these missions and the requirements of other developing technologies that will be required. Nuclear thermal propulsion offers a significant improvement over chemical propulsion while still achieving high levels of thrust. Opportunities exist; however, to build upon what would be considered a standard nuclear thermal engine to attain improved performance, thus further enabling deep space missions. This paper discuss the modeling of a nuclear thermal system integrated with an arc jet to further augment performance. The performance predictions and systems impacts are discussed.
\end{abstract}

\section{Nomenclature}

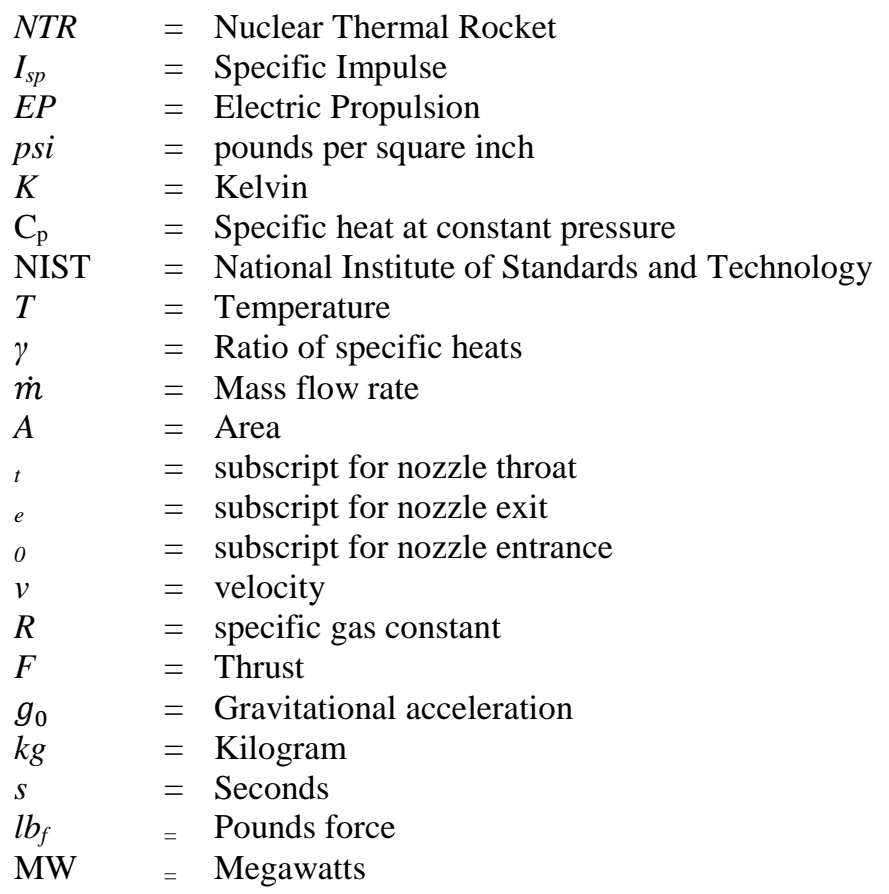

\section{Introduction}

$\mathrm{W}$ ith the development of commercial space flight and the progression of the commercial crew program, many low earth orbit activities are transitioning to the private sector. This will soon include transportation of

\footnotetext{
${ }^{1}$ Rocket Propulsion Systems Engineer, Propulsion Systems Department, ER22, AIAA Member.

${ }^{2}$ Senior Engineer, Propulsion Systems Department, ER24, and AIAA Associate Fellow.
}

American Institute of Aeronautics and Astronautics 
astronauts to and from the international space station. As this transition takes place, NASA is becoming more focused on deep space exploration. There are many different concepts and destinations for deep space exploration that have been discussed in the ongoing public discussion. Some examples include missions utilizing Lagrange points, and visiting or recovering an asteroid. The destination which has long since captured the imagination is Mars. There are several different concepts concerning the future exploration of Mars, including concepts involving missions to the moons Phobos and Deimos. Manned missions to Mars are very ambitious and will require the development of many technologies and thorough logistical planning.

Deep space exploration missions, such as manned Mars missions, face many technological challenges that must be considered and resolved far in advance of any mission. For this reason, current technology development is critical to achieving NASA roadmap goals for deep space exploration in our life time. Many of these challenges are in regards to the development of propulsion systems that can meet mission requirements. The propulsion system for a vehicle that will carry astronauts and equipment to Mars must meet a number of requirements, including operating as efficiently as possible and providing enough thrust for the astronauts to reach Mars in a reasonable amount of time.

A manned mission to Mars will require a payload much larger than anything ever before sent to the Martian surface. This will likely be supported by smaller cargo vehicles sent in advance of the astronauts. While the cargo missions can operate over longer periods of time and utilize highly efficient solar powered propulsion systems, the manned vehicle must traverse to Mars at a much faster rate. The manned Mars transfer vehicle will be required to operate as efficiently as possible while still providing enough power and delta $\mathrm{V}$ (velocity vector change due to the thrust of the propulsion system) to achieve desired flight times between Earth and Mars. The efficiency of the propulsion system relates how much thrust is gained from a unit mass of propellant. The large quantities of thrust and delta $\mathrm{V}$ needed in this mission amounts to significant quantities of propellant that must be lifted into orbit, carried, and stored (cryogenically). The cost and achievability of a manned mission to Mars will be sensitive to the required quantity of propellant and thus the efficiency of the propulsion system as well as the size of the propulsion system itself. The efficiency can be characterized by the term specific impulse $\left(\mathrm{I}_{\mathrm{sp}}\right)$. Specific impulse is defined as the ratio of total impulse to mass of consumed propellant and has units of seconds. The best chemical engines available today provide high thrust but specific impulse values of approximately 400 to 450 seconds at best. Electric propulsion systems currently available are highly efficient with specific impulse values in the thousands, but are low thrust systems. This results in long flight times. Nuclear thermal propulsion systems; however, are capable of providing high thrust at a specific impulse that is double that of the best chemical engines (Isp in the 800 to 900 seconds range). This makes nuclear propulsion and attractive option for a Mars transfer vehicle. Existing knowledge and past programs permit a nuclear thermal engine development to be achievable in the time frame of NASA roadmaps for manned Mars missions.

The use of nuclear power a spacecraft's propulsion system has gained renewed interest in recent years as the National Aeronautics and Space Administration (NASA) is progressing down a developmental and operational path to sending astronauts to Mars. Research started on nuclear propulsion systems at Los Alamos Scientific Laboratory under Project Rover in the 1950's. The Nuclear Engine for Rocket Vehicle Application (NERVA) program, which was a joint effort between NASA and the Atomic Energy Commission, was a development program for a nuclear thermal propulsion system. Rover/NERVA developed and tested several reactor and nuclear thermal engine system designs. This program ended in the early 1970's. In recent years, work has been done in design cycle studies, power balance models, system trades, planning for logistics as well as ground tests, and component technology development. It is apparent based on past work that even with ideal technology development, logistics, and resources the performance of a nuclear thermal propulsion system will still require a large quantity of propellant and thus a significant, resource intensive operation. It is therefore desirable to increase the performance of a nuclear thermal propulsion system in any way we can despite the fact that it is more efficient at equivalent power levels than chemical engines.

One concept to further improve the performance of a nuclear thermal propulsion system is to augment the energy in the propellant prior to expansion through a nozzle with an electric propulsion system. An Arc Jet is an example of such a system. Heat augmentation systems, such as this, have been considered impractical in the past due to the difficulty in generating large quantities of electrical energy. Most of these difficulties stem from the assumption that huge radiators would be required to dissipate the large amount of waste heat resulting from the cycle power conversion process. A way around this is to reject the heat directly to the propellant in an open loop configuration. Therefore, by designing the reactor for a two pass system, one can extract energy for electricity production and send non-extracted heat and propellant back through the reactor for thrust generation.

One might consider other approaches as well when trying to improve Nuclear Thermal Rocket (NTR) performance. A conventional nuclear reactor in the propulsion system is limited in the energy that can be extracted by the rate of heat transfer to the propellant and the temperature limits of the reactor materials. Consequently, the nuclear reactor is

American Institute of Aeronautics and Astronautics 
capable of producing far more energy than can be extracted. Alternatives to the fuel rod design may be considered. One such concept is a grooved fuel ring design, studied separately by one of the authors, Dr. Emrich, increases the heat transfer to the propellant and thus propellant temperature due to greater surface area of the fuel in contact with the propellant.

The authors sought to develop a model to predict the performance of an integrated NTR-Arc Jet system. A baseline of assumptions was developed based on state of the art technology and developing capabilities. The said model was built in Matlab. The model was used to vary several parameters in order to gain an understanding of performance improvement over a single pass "standard" NTR. Additionally, the authors analyzed the effect of component efficiency upon performance. Also an analysis of the impacts of this configuration on the larger stage system was conducted. This work is presented below.

\section{NTR-Arc Jet System Description}

While Nuclear Thermal Rockets or NTRs offer the promise of specific impulse values approximately twice as high as the best chemical systems, their performance is still somewhat marginal when considering certain manned Mars or other challenging deep space mission assignments. As discussed above, one method by which the performance of NTR systems could potentially be improved would be to add further energy to the propellant through an arc jet or perhaps another electric propulsion device.

In this engine cycle, the propellant gains energy in the reactor as usual, however, instead of being exhausted through a nozzle, the propellant is introduced directly into a large turbopump assembly which powers both the propellant pump and an electrical generator. Since the propellant pump requires very little power compared that available from the turbine, the excess power could be used to drive an electrical generator which would in turn drive an arc jet or perhaps another electric propulsion (EP) thruster. The exhaust from the turbine would be directed back through the reactor core where it would be reheated and subsequently directed into the arc jet or EP thruster where even higher temperatures would be achieved. The super-hot propellant exiting the arc jet or EP thruster would then finally be exhausted from the engine to produce thrust. A diagram of the engine cycle is displayed in Figure 1. The high temperature of the propellant results in higher specific impulse ( $\left.\mathrm{I}_{\mathrm{SP}}\right)$ and Thrust.

Such a system will have a larger reactor and possibly a lower thrust to weight ratio. Since the propellant is essentially "dumped" overboard to produce thrust in this rocket cycle, there is no need for a heat rejection system to take care of the waste heat which would normally be necessary if the power cycle were closed. It should be noted that this engine cycle operates best at high pressures since the temperature increase results mainly from turbine $\Delta \mathrm{P}$ work. Using multistage turbines and allowing the reactor to operate at higher exit temperatures could potentially allow even higher outlet temperature from the arc jet to be achieved.

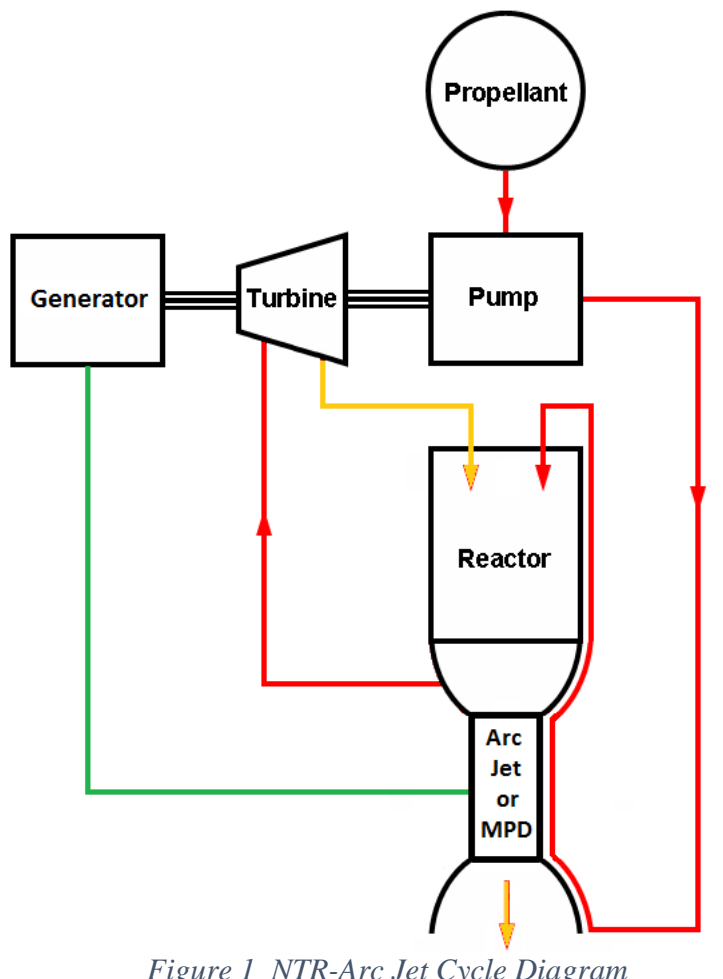

\section{Model and Assumptions}

The power balance model of the integrated NTR - Arc Jet system was built on assumptions that brought the model to the level of fidelity desired for this study. The assumptions were chosen based on existing data and experience. In addition to that, the authors understanding of the state of the art engine component performance and "common" engine characteristics were used. These baseline assumptions were used to define the parameter space of the model calculations. The assumptions are described in this section along with a description of the model calculations.

\section{A. Assumptions}

The authors start by assuming the working propellant is liquid hydrogen. It is set to enter the pump at 40 psi at 20

$\mathrm{K}$. The value for specific heat at constant pressure, $\mathrm{C}_{\mathrm{p}}$, is assumed constant; however, two values are used. A

American Institute of Aeronautics and Astronautics 
cryogenic value and a "hot" value are used as appropriate throughout the model. The $\mathrm{C}_{\mathrm{p}}$ of the propellant is taken from data obtained from the program Refprop. This program is available from the National Institute of Standards and Technology (NIST).

The flow is isentropically compressed across the pump to high pressure which vary across the parameter space. Pressure losses in the ducts and components are neglected in this model. Properties are held constant along ducting between components. It is assumed this engine will be equipped with regenerative cooling in the nozzle. This rise in temperature is set at $500 \mathrm{~K}$. The propellant makes two passes through the reactor in which it picks up enthalpy. During the first pass, the pressure is taken to remain constant through the reactor and the exit temperature of the propellant is set to 2,000 K. This is the temperature at which the propellant will enter the turbine. This is high compared to state of the art turbine temperature; however, Mitsubishi has published research on turbines operating at temperature approaching $2,000 \mathrm{~K} .{ }^{1,2}$ This is important because the enthalpy change across the turbine determines the quantity of electricity generated.

The propellant flows into the turbine after the first pass through the reactor. The turbine is assumed to operate at an efficiency of $80 \%$ and expand the flow isentropically. State of the art turbine technology is expected to be capable of reaching this efficiency. The propellant exiting the turbine flows back through the reactor where it exits at a temperature of $3,000 \mathrm{~K}$. This temperature is expected to be the max achievable due to fuel temperature limitations.

Table 1 Summary of Model Assumptions

\begin{tabular}{|c|c|}
\hline 1 & $\begin{array}{c}\text { Hydrogen is propellant stored at } \\
40 \text { psi and 20 K. }\end{array}$ \\
\hline 2 & $\begin{array}{c}\text { Isentropic compression/expansion } \\
\text { processes through pump and } \\
\text { turbine }\end{array}$ \\
\hline 3 & No pressure losses \\
\hline 4 & $\begin{array}{c}\text { 500 K propellant temperature after } \\
\text { regenerative cooling }\end{array}$ \\
\hline 5 & Turbine Efficiency $80 \%$ \\
\hline 6 & Generator Efficiency 95\% \\
\hline 7 & Arc Jet Efficiency 50\% \\
\hline 8 & $\begin{array}{c}\text { Propellant Temperature 2,000 K } \\
\text { after first pass through Reactor }\end{array}$ \\
\hline 9 & $\begin{array}{c}\text { Propellant Temperature 3,000 K } \\
\text { after first pass through Reactor }\end{array}$ \\
\hline 10 & Arc Jet has bulk heating effect \\
\hline 11 & $\begin{array}{c}\text { Energy loss to dissociation is } \\
\text { negligible }\end{array}$ \\
\hline 12 & $\begin{array}{c}\text { Constant specific heat at hot and } \\
\text { cold conditions }\end{array}$ \\
\hline 13 & $\begin{array}{c}\text { 200 area ratio nozzle operating in } \\
\text { vacuum }\end{array}$ \\
\hline 14 & $\begin{array}{c}\text { Turbine inlet max temperature is } \\
\text { 2,000 K }\end{array}$ \\
\hline
\end{tabular}

The turbine powers both the pump and a generator. The generator is assumed to operate at $95 \%$ efficiency. The electricity from the generator powers the arc jet which adds energy to the propellant after exiting the nozzle on the second pass, but before entering the nozzle. The arc jet is modeled as a bulk heating mechanism. A value of $50 \%$ was used for arc jet efficiency. It is expected, based on past work, that an arc jet could reach this range of efficiency. ${ }^{5}$ At these temperature, small percentages of the flow will dissociate. The decrease in temperature due to energy lost to dissociation is assumed negligible.

Once the propellant has picked up energy from both the reactor and the arc jet, it is expanded through a nozzle to create thrust. The nozzle is given an area ratio of 200 and is assumed to operate in a vacuum. The isentropic flow equations are used to calculate flow properties through the nozzle to obtain thrust and $\mathrm{I}_{\mathrm{sp}}$ values. The assumptions are summarized in the Table 1.

\section{B. Model Calculations}

The integrated NTR-Arc Jet system was modeled using Matlab. A series of Matlab files were created to run the calculations for the power balance and vary several parameters. It also generates several plots that summarize system performance.

Pump and turbine processes are isentropic. Flow properties are therefore determined with isentropic flow relations between temperature and pressure for up and downstream propellant properties. Equation 1 shows this relationship. ${ }^{3}$

$$
\frac{T_{1}}{T_{0}}=\left(\frac{P_{1}}{P_{0}}\right)^{\frac{\gamma-1}{\gamma}}
$$

Changes in enthalpy that occur in the pump, turbine, reactor and arc jet are found assuming constant specific heat. This makes the enthalpy change a function of mass flow rate and temperature change. This equation is presented in Equation 2. ${ }^{3}$

American Institute of Aeronautics and Astronautics 


$$
\Delta H=\dot{m} C_{p}\left(T_{2}-T_{1}\right)
$$

Dissociation is accounted for in the hot hydrogen following the heating process in the arc jet. Data points for percent dissociation for a range of temperature and pressure were recorded from the software CEA (Chemical Equilibrium with Applications). The data points were used to interpolate the percent dissociation of the flow as a function of temperature and pressure. This in turn was used to find the average molecular weight of the gas.

The nozzle is considered to be isentropic. Exit pressure can be solved for numerically using the equation for area ratio, which is a function of pressure ratios and the ratio of specific heats. The flow relations then define the velocity of the propellant at the nozzle exit. This in turn is used to find the thrust and specific impulse of the engine. These relationships are presented in Equations 3 through 6 below. ${ }^{3}$

$$
\begin{gathered}
\frac{A_{t}}{A_{e}}=\frac{\gamma+1 \frac{1}{\gamma-1}}{2}\left(\frac{P_{e}}{P_{0}}\right)^{\frac{1}{\gamma}} \sqrt{\frac{(\gamma+1)}{\gamma-1}\left[1-\left(\frac{P_{e}}{P_{0}}\right)^{\frac{\gamma-1}{\gamma}}\right]} \\
v_{e}=\sqrt{\frac{2 \gamma}{\gamma-1} R T_{0}\left[1-\left(\frac{P_{e}}{P_{0}}\right)^{\frac{\gamma-1}{\gamma}}\right]} \\
F=\dot{m} v_{e} \dot{+} P_{e} A_{e} \\
I_{s p}=\frac{F}{\dot{m} g_{0}}
\end{gathered}
$$

The greater Matlab model uses functions and loops to vary pump discharge pressure, turbine exit pressures, and mass flow rates. Various other parameters can be adjusted to explore performance at additional conditions. The results of this model are presented in the following section.

\section{Results}

The performance of the engine system is described in a series of plots that vary the mass flow rate, pump outlet pressure and the exit pressure of the turbine. Three mass flow rates $(5 \mathrm{~kg} / \mathrm{s}, 10 \mathrm{~kg} / \mathrm{s}$ and $20 \mathrm{~kg} / \mathrm{s})$ were used to present performance for different engine sizes. Most of the performance values are presented as functions of the turbine inlet pressure for multiple chamber pressures. It should be noted that the outlet pressure of the turbine is the pressure at the entrance to the nozzle and is referred to as chamber pressure. The results using the baseline assumptions are presented in the first subsection, while additional parameters are varied in subsequent section to speculate on the impact of technology advances on engine performance.

For reference, the performance values were found for the smallest engine (mass flow rate of $5 \mathrm{~kg} / \mathrm{s}$ ) with a 0 percent efficiency in the arc jet in order to give a sense of arc jet effect. The thrust with no arc jet was $10,190 \mathrm{lb}_{\mathrm{f}}$ and the $\mathrm{I}_{\mathrm{sp}}$ was $920 \mathrm{~s}$. These values correspond to a chamber temperature of 3,000 K.

American Institute of Aeronautics and Astronautics 


\section{A. Baseline Results}

\section{Reactor Power}

The reactor power for the integrated NTR-Arc Jet system is determined from the change in enthalpy in the first and second passes of the propellant through the reactor. It is measured in MW and plotted as a function of turbine inlet pressure. The reactor power is plotted for various chamber pressures, which is the pressure at the nozzle entrance. One can see that the reactor power increases as the turbine inlet pressure increases, the effect levels off. The decrease in chamber pressure, thus an increase in pressure ratio, also results in higher reactor power; however. Figures 2,3 and 4 plot the reactor power for the three engine sizes. Power levels vary significantly between 280 and 360 MW for the small engine size to 1100 to $1450 \mathrm{MW}$ for the largest size engine.

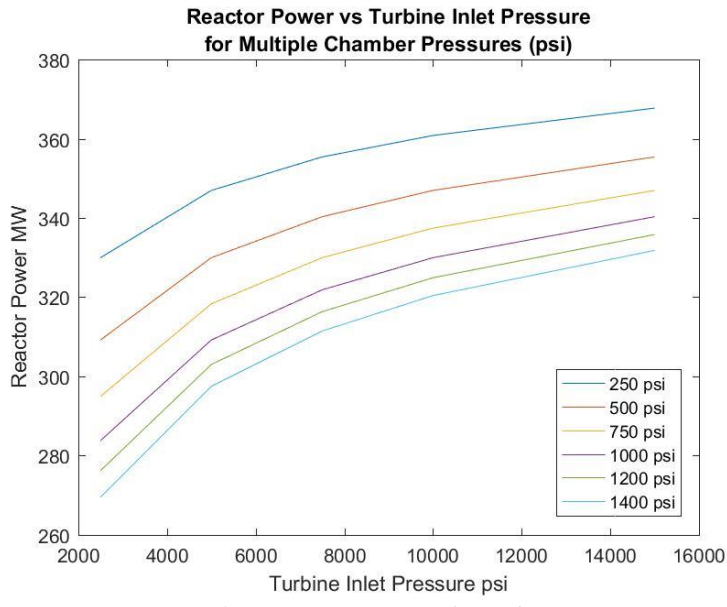

Figure 2 Reactor Power for $5 \mathrm{~kg} / \mathrm{s}$ Engine

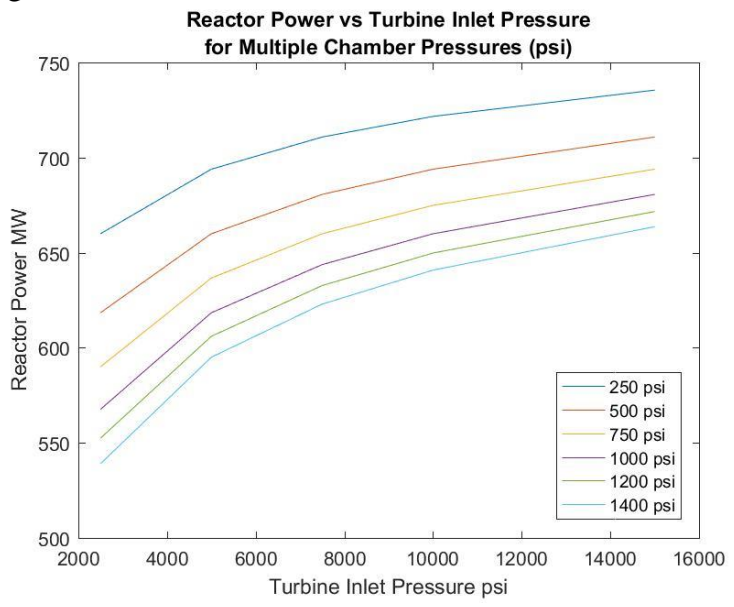

Figure 3 Reactor Power for $10 \mathrm{~kg} / \mathrm{s}$ Engine

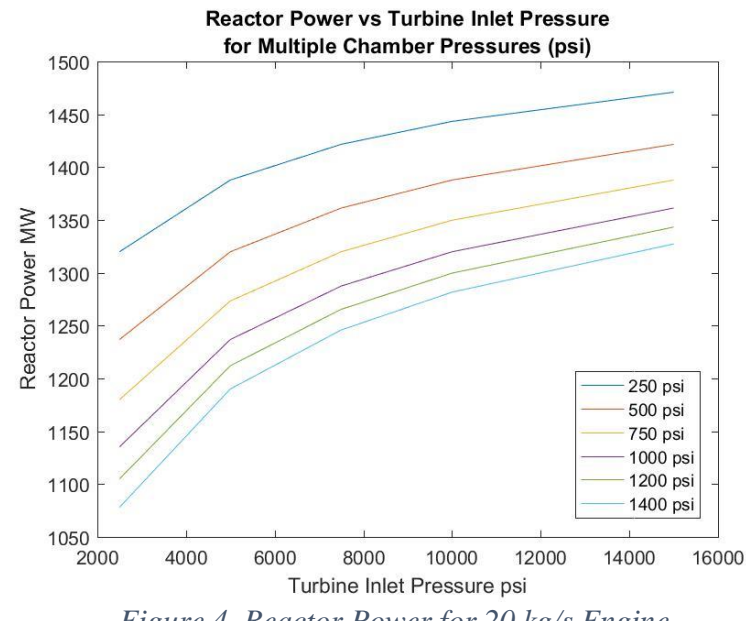

Figure 4 Reactor Power for $20 \mathrm{~kg} / \mathrm{s}$ Engine

\section{Turbine Power}

The power generated by the turbine is found by determining the enthalpy change across the expansion process. This is defined by the designated pressures. The portion of the energy extracted by the turbine that is not required by the pump is sent to the generator. There it is converted to electricity and sent to the arc jet. Like the reactor power, the turbine power is measured in MW and plotted against the turbine inlet pressure. Trends are similar to that of the reactor. The turbine power increases with increasing inlet pressure and decreasing outlet pressure of the turbine. The increase with pressure ratio levels off at large turbine inlet pressure values. Turbine power for the small engine is in the vicinity of 40 to $120 \mathrm{MW}$. The turbine of the largest engine generates power in the range of 150 to $500 \mathrm{MW}$. Figures 5, 6 and 7 show the turbine power calculations. 


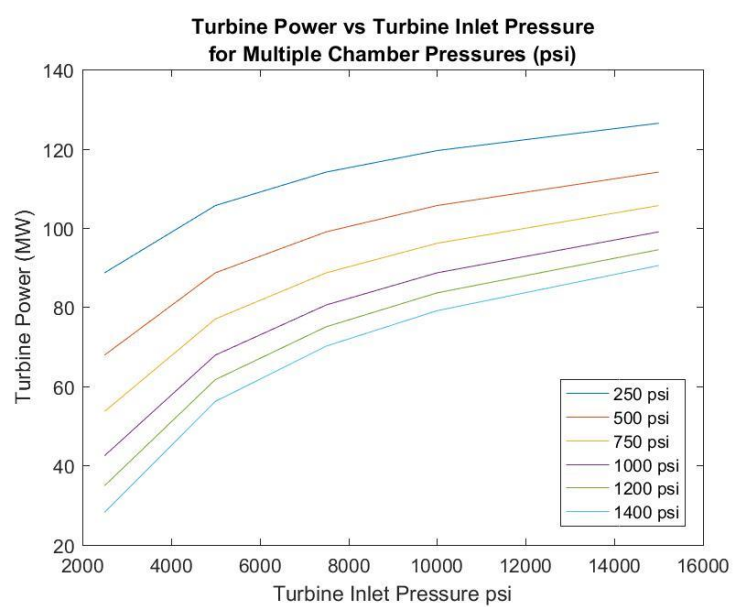

Figure 5 Turbine Power for $5 \mathrm{~kg} / \mathrm{s}$ Engine

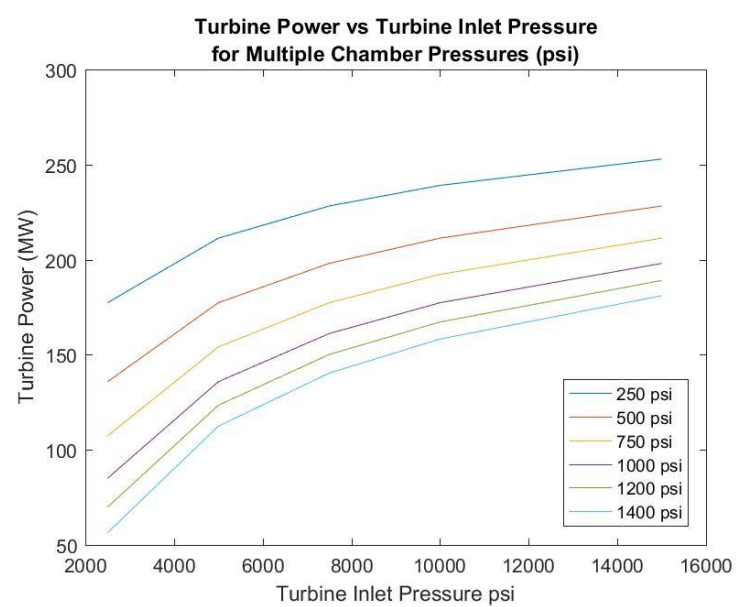

Figure 6 Turbine Power for $10 \mathrm{~kg} / \mathrm{s}$ Engine

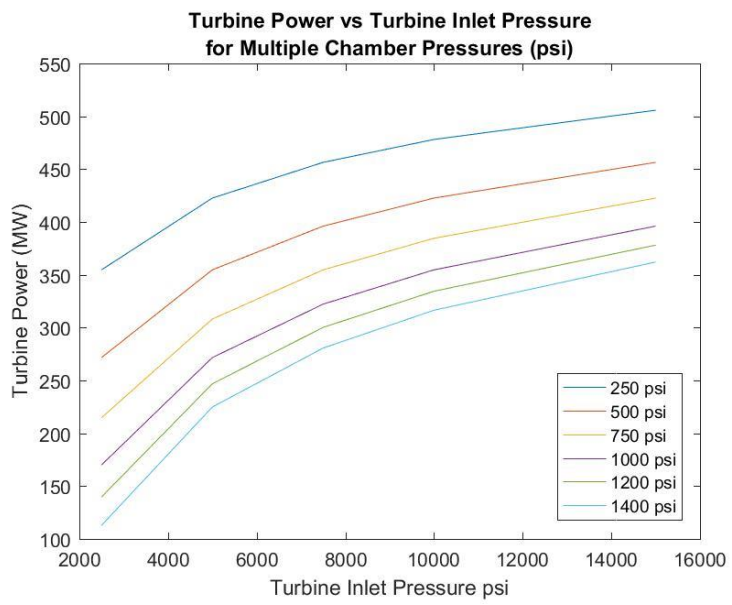

Figure 7 Turbine Power for $20 \mathrm{~kg} / \mathrm{s}$ Engine

\section{Arc Jet Power}

There is a large drop in available energy from the arc jet due to the efficiency of the generator and arc jet. The available energy is still significant; however, and will raise the temperature of the propellant, thus providing additional energy that can be converted to thrust. The energy added to the propellant by the arc jet is assumed to be in the form of bulk heating, thus heating all the propellant evenly.

Again one can see that the arc jet power increases with increasing turbine inlet pressure and decreasing chamber pressure. This is due to the level of flow expansion in the turbine. The more the engine expands the flow in the turbine, the more energy is available to power the arc jet. The effect once again levels off with high turbine inlet pressures. Thus there is a diminishing return, which suggests an optimal pressure ratio that is balanced with increased weight and other negative impacts of the system. Arc jet power for the smallest system ranges from 10 to $40 \mathrm{MW}$ and 40 to $160 \mathrm{MW}$ for the largest engine system. See Figures 8 through 10 for the arc jet power plots.

American Institute of Aeronautics and Astronautics 


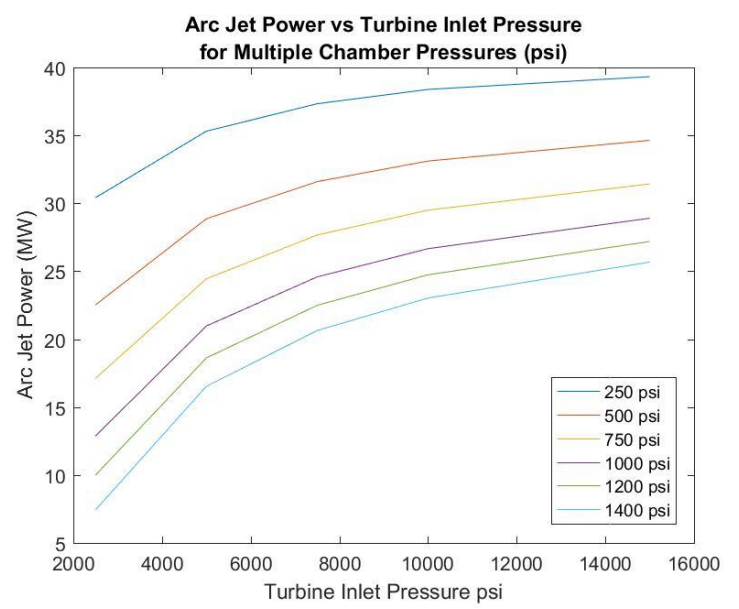

Figure 8 Arc Jet Power for $5 \mathrm{~kg} / \mathrm{s}$ Engine

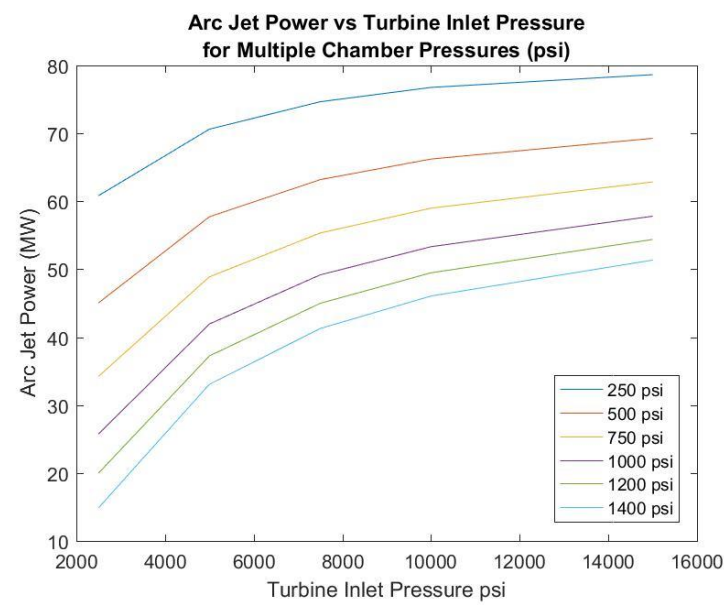

Figure 9 Arc Jet Power for $10 \mathrm{~kg} / \mathrm{s}$ Engine

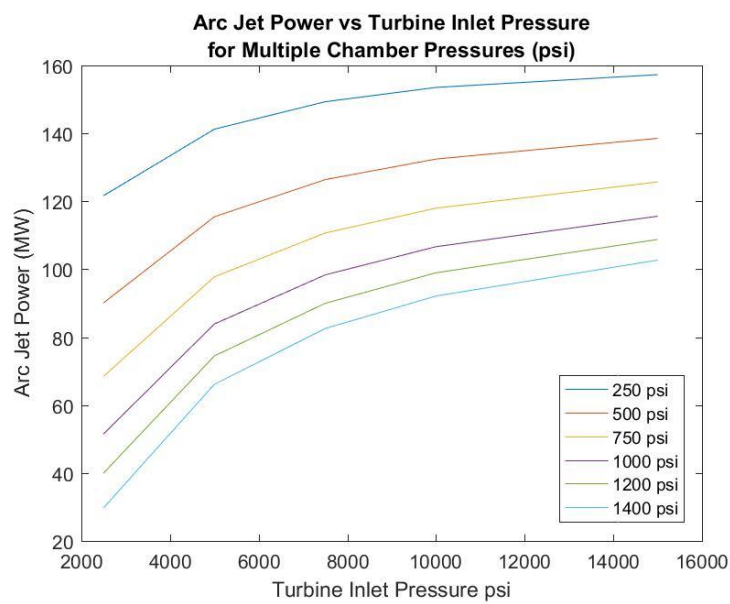

Figure 10 Arc Jet Power for 20 kg/s Engine

\section{Chamber Temperature}

The chamber temperature is calculated following the energy deposition of the arc jet. This is found using the equation for a change in enthalpy which occurs across the arc jet. The exit velocity and average molecular weight of the gas is dependent upon the chamber temperature of the propellant. This in turn means the thrust of the engine and the specific impulse are strongly dependent on the temperature of the propellant as it enters the nozzle. The temperature represents the energy potential available to convert to kinetic energy and thus thrust. The higher the propellant temperature, the more powerful and efficient the engine. In this model the Chamber temperature is independent of engine size and mass flow rate. This is because, with greater mass flow, the reactor grows proportionately and more energy is available to the propellant. The chamber temperatures calculated range between $3100 \mathrm{~K}$ and $3500 \mathrm{~K}$. Temperature grow with turbine inlet pressure and greater expansion. The amount of energy that can be extracted tails off at large pressure values at the turbine inlet; therefore, so does chamber temperature. Figure 11 plots the chamber pressure as a function of turbine inlet pressure for various chamber pressures.

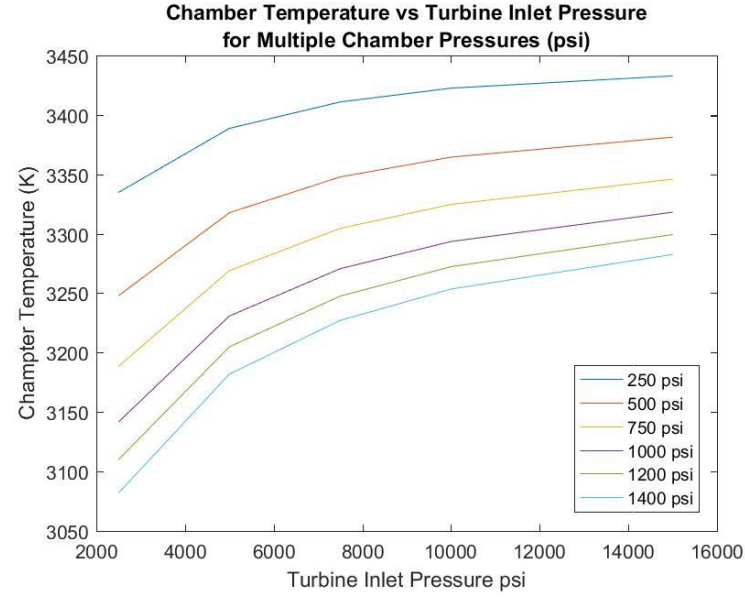

Figure 11 Chamber Temperature

American Institute of Aeronautics and Astronautics 


\section{Thrust}

This integrated engine system can be easily scaled to different sizes by changing the propellant mass flow rate. The thrust and specific impulse will change accordingly. The thrust is found after calculating the exit pressure, average molecular weight and exhaust velocity. The thrust level changes with turbine inlet pressure and turbine expansion. The greater pressure ratio and expansion, the higher the available thrust. Thrust capability tapers off with high pressure ratios. The $5 \mathrm{~kg} / \mathrm{s}$ mass flow rate engine has thrust values a bit higher than $10,000 \mathrm{lb}$, while the $10 \mathrm{~kg} / \mathrm{s} \mathrm{mass} \mathrm{flow}$ rate brings the engine up just over $21,000 \mathrm{lb}_{\mathrm{f}} .20 \mathrm{~kg} / \mathrm{s}$ results in a thrust of about $42,500 \mathrm{lb}_{\mathrm{f}}$. See Figures 12 through 14 for the plots of thrust versus turbine inlet pressure and plotted for several chamber pressures.

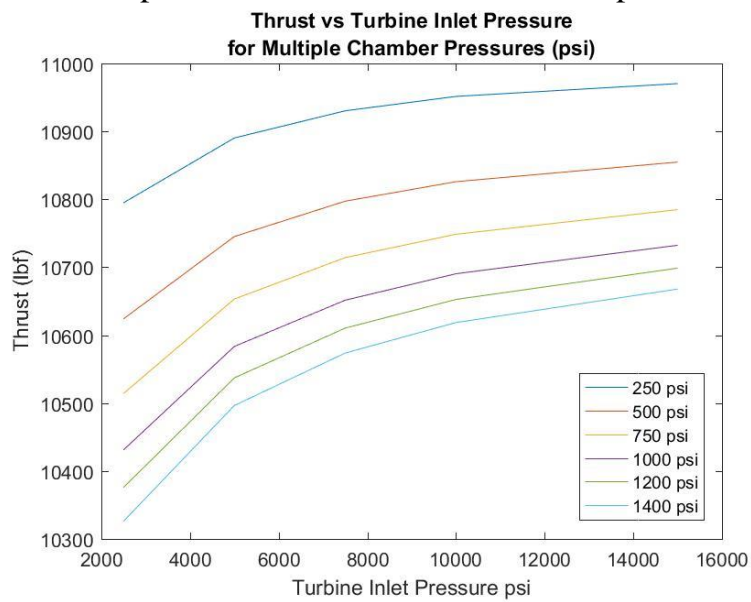

Figure 12 Thrust for the $5 \mathrm{~kg} / \mathrm{s}$ Engine

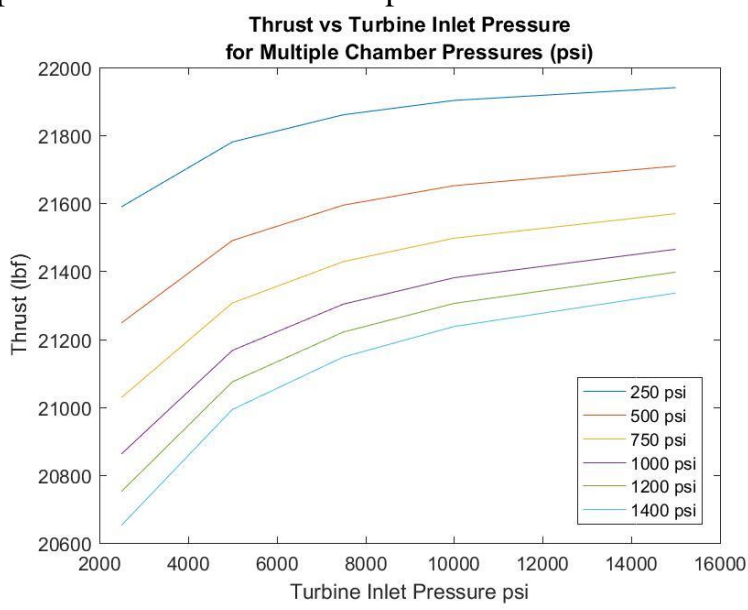

Figure 13 Thrust for the $10 \mathrm{~kg} / \mathrm{s}$ Engine

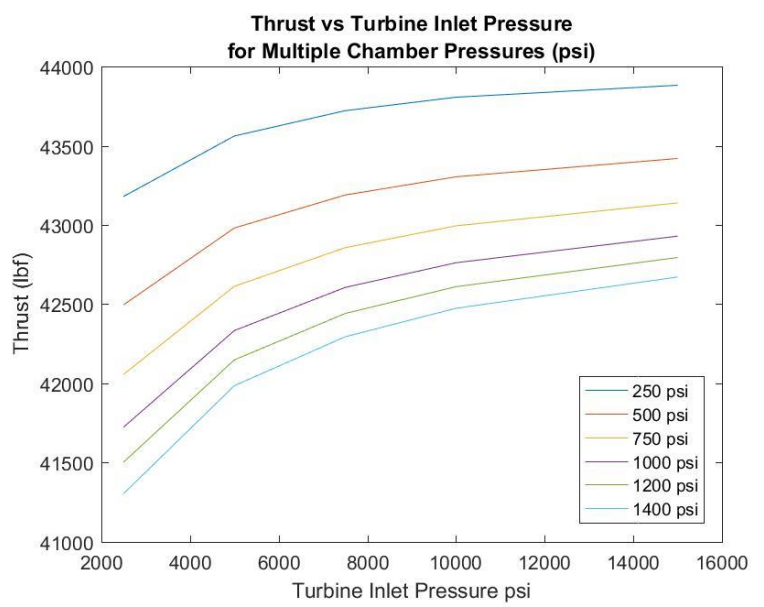

Figure 14 Thrust for the $20 \mathrm{~kg} / \mathrm{s}$ Engine

\section{Specific Impulse}

The final performance number calculated is that of specific impulse. Specific impulse is the ratio of impulse per unit of mass flow. This makes it a good indicator of engine efficiency. The specific impulse is plotted in Figure 15. The plot lines of specific impulse increase for greater turbine expansion since more energy is extracted. This increases efficiency. Higher turbine inlet pressure increases specific impulse as well, but once again tail off with high pressure ratios. The specific impulse is independent of mass flow rate in the same way as chamber pressure. It can be seen in Figure 15, that with baseline assumption, specific impulse of up to 990 can be reached.

American Institute of Aeronautics and Astronautics

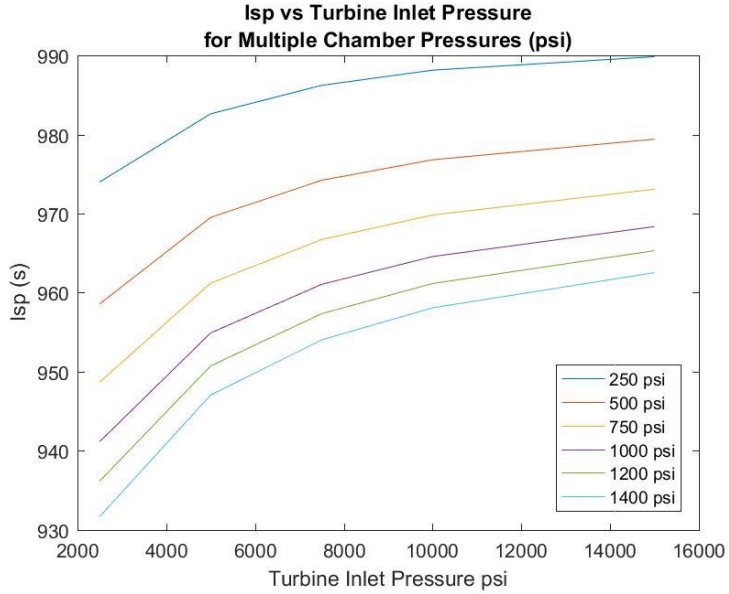

Figure 15 Specific Impulse of the NTR-Arc Jet System 


\section{B. Model Results with Further Technology Advances}

\section{Greater Arc Jet Efficiency}

Among the factors limiting performance of this system is that of arc jet efficiency. Existing test data was reviewed in order to understand the current limitations of arc jet systems. Recent testing has shown that the current limit of arc jet efficiency is approximately 50\%. ${ }^{5}$ About half the energy is lost. It is; therefore, highly desirable to invest in higher efficiency arc jets or other electric propulsion systems. Greater efficiency puts more energy into the propellant and reduces the waste heat.

If one runs the model and increases the arc jet efficiency to $80 \%$ the improved performance numbers can be compared to those of the previous section. This was done for the $5 \mathrm{~kg} / \mathrm{s}$ mass flow rate case. Figures 16 through 19 display these results. One can see that the arc jet power increases from a maximum of about $40 \mathrm{MW}$ to a bit over 60 MW. The chamber temperature increases by about $300 \mathrm{~K}$. The increase in efficiency also raises the thrust by approximately $450 \mathrm{lb}_{\mathrm{f}}$ and the $\mathrm{I}_{\mathrm{sp}}$ by 40 seconds. These results can be seen in Figures 16 through 19.

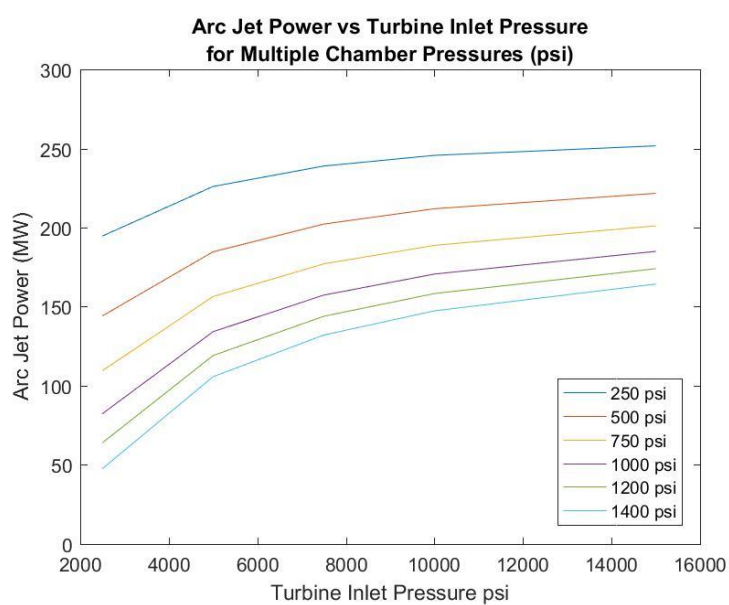

Figure 16 Arc Jet Power with Increased Efficiency

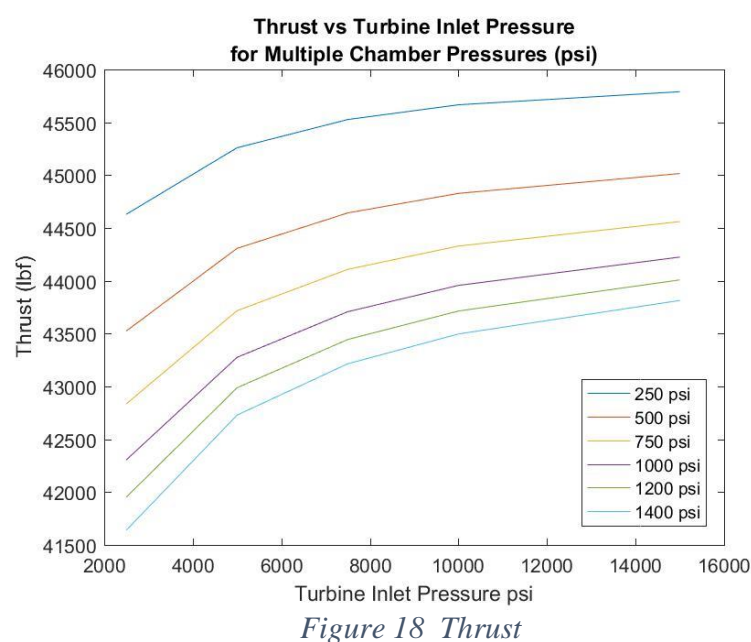

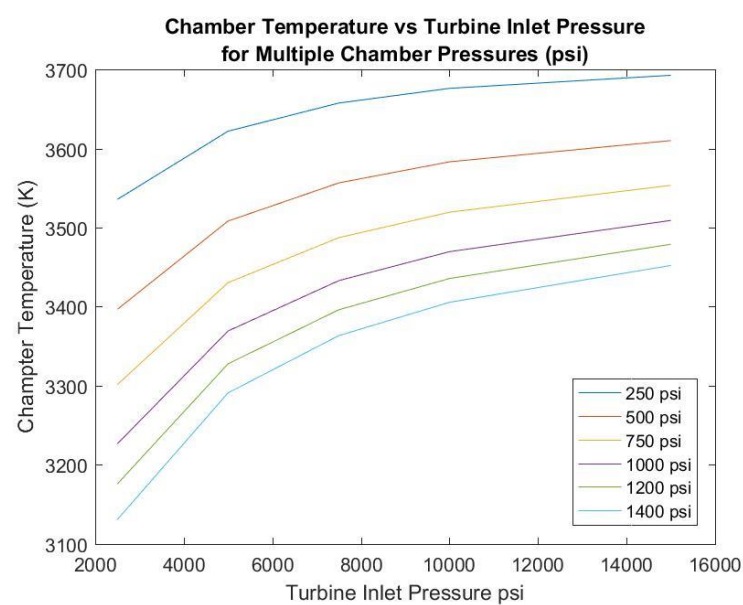

Figure 17 Chamber Temperature

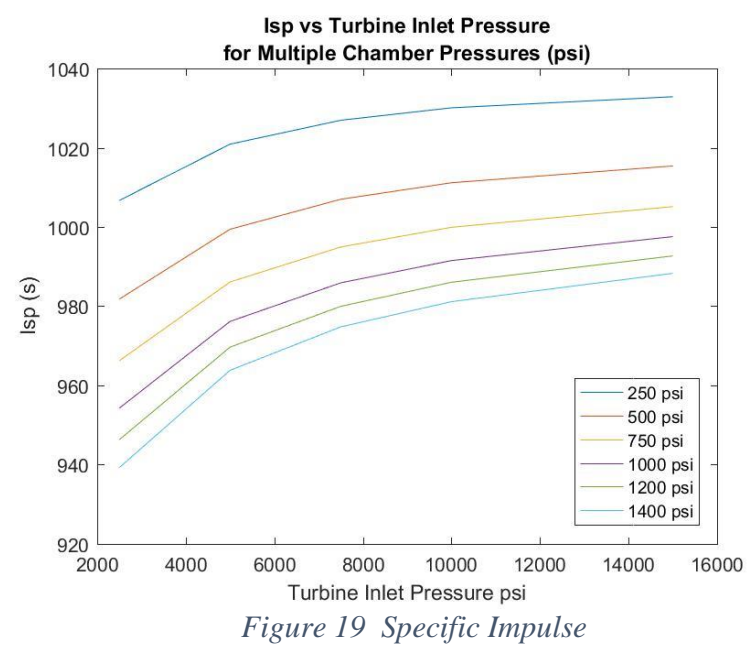

\section{Higher Turbine Temperature Limit}

In the baseline model the temperature of the propellant entering the turbine was limited to 2,000 K. Advanced turbine technology in development by Mitsubishi has shown testing about up to this temperature. ${ }^{1,2}$ Higher temperatures will require further technology and material advances.

The amount of enthalpy available for extraction by the turbine is, in part, a function of the temperature of the flow at the inlet. By increasing the temperature limitation of the turbine, one can generate more energy by expanding the flow. The reactor can be sized to produce more energy and high propellant temperatures at the exit of the first pass. Although current material properties limit how hot of a flow the turbine blades can experience, it is interesting to note

American Institute of Aeronautics and Astronautics 
how hotter flows will increase performance. Investment in higher temperature turbines may be worthwhile given the potential performance improvements to this engine system and others.

The model was rerun using a temperature limit for the turbine of $2800 \mathrm{~K}$ for the $5 \mathrm{~kg} / \mathrm{s}$ mass flow rate case. Turbine Power is shown to increase by almost $50 \mathrm{MW}$ while the arc jet increase by about $20 \mathrm{MW}$. Chamber temperature increases by about $200 \mathrm{~K}$. This improve thrust and specific impulse by about $400 \mathrm{lb}_{\mathrm{f}}$ and 35 seconds respectively. These results are plotted in Figures 20 through 25.
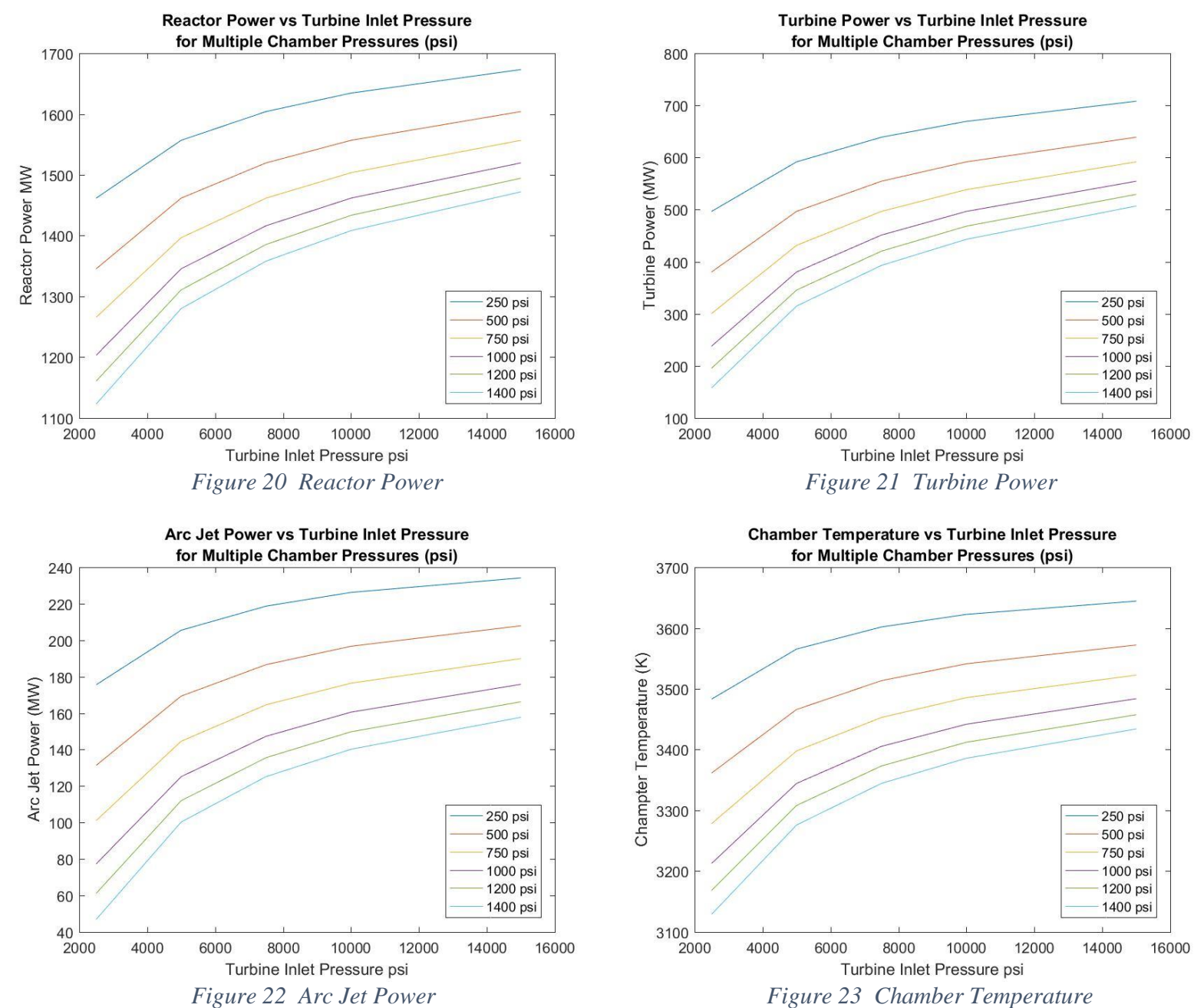

Figure 23 Chamber Temperature 

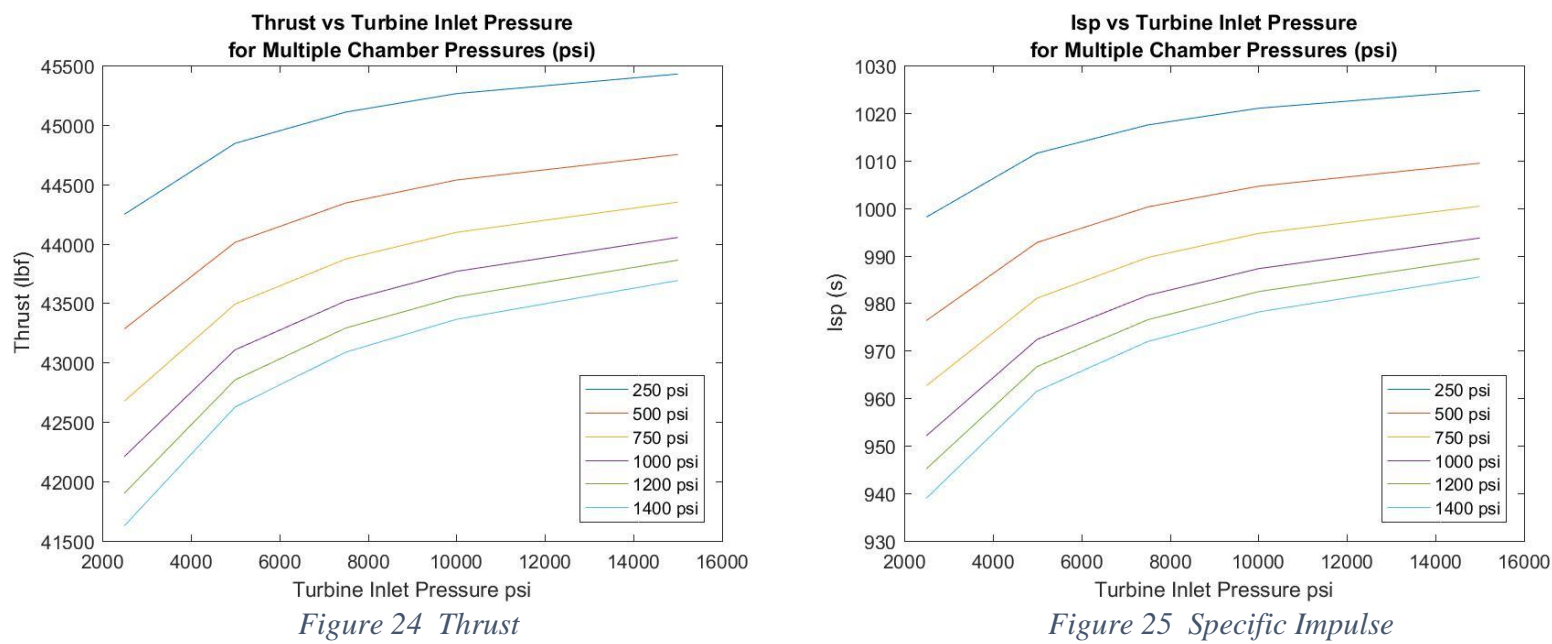

3. Combined Increase of Arc Jet Efficiency and Turbine Temperature Limit

Pushing the limitations through advanced technology development can have significant impact upon engine performance. This is especially true if multiple advanced technologies can be applied such that their effect is cumulative. If the efficiency of an arc jet, or perhaps another electric propulsion system, can be increased while simultaneously raising the temperature limit of the turbine, then greater performance improvement can be achieved.

The model was modified to run with an arc jet efficiency of $80 \%$ and a temperature limit for the turbine of 2800 $\mathrm{K}$. Turbine power is once again raised by about $50 \mathrm{MW}$, but with the higher arc jet efficiency the arc jet power is raised by about $55 \mathrm{MW}$. Chamber temperature increases by about $600 \mathrm{~K}$ with the added energy. With the temperature increase in the chamber, the thrust increases by about $1100 \mathrm{lb}_{\mathrm{f}}$ and the specific impulse improves by about 100 seconds. These results can be viewed in Figures 26 through 31 .

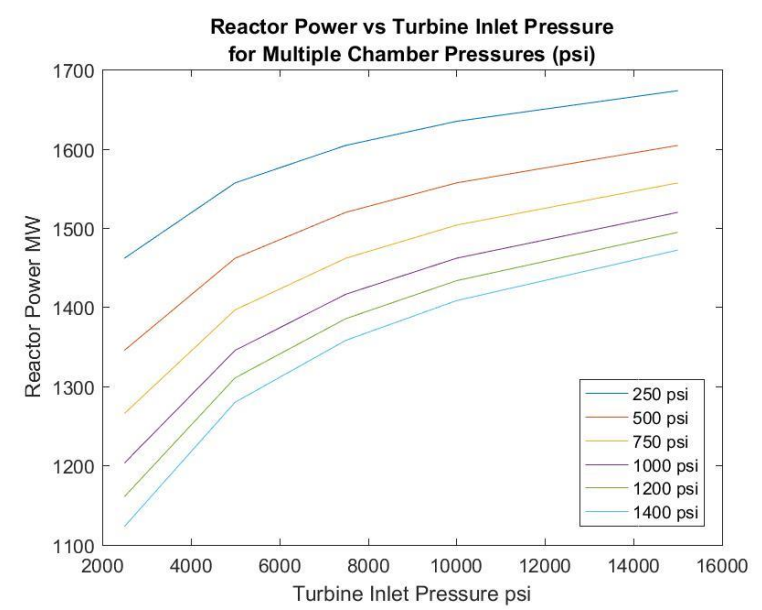

Figure 26 Reactor Power

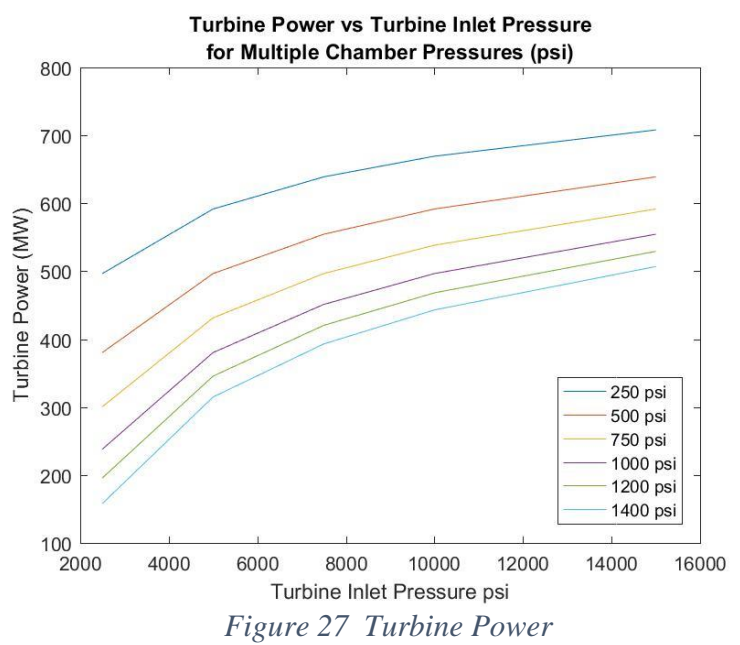

Figure 27 Turbine Power 

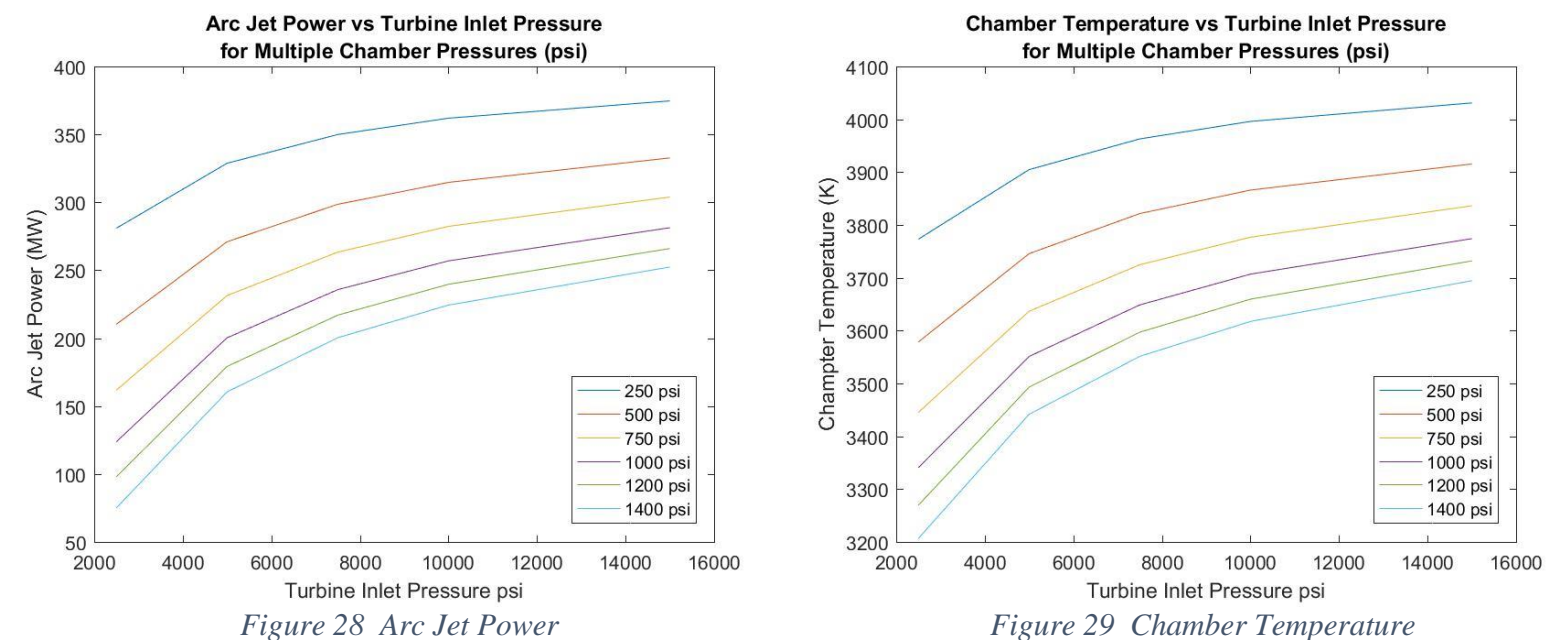

Figure 29 Chamber Temperature
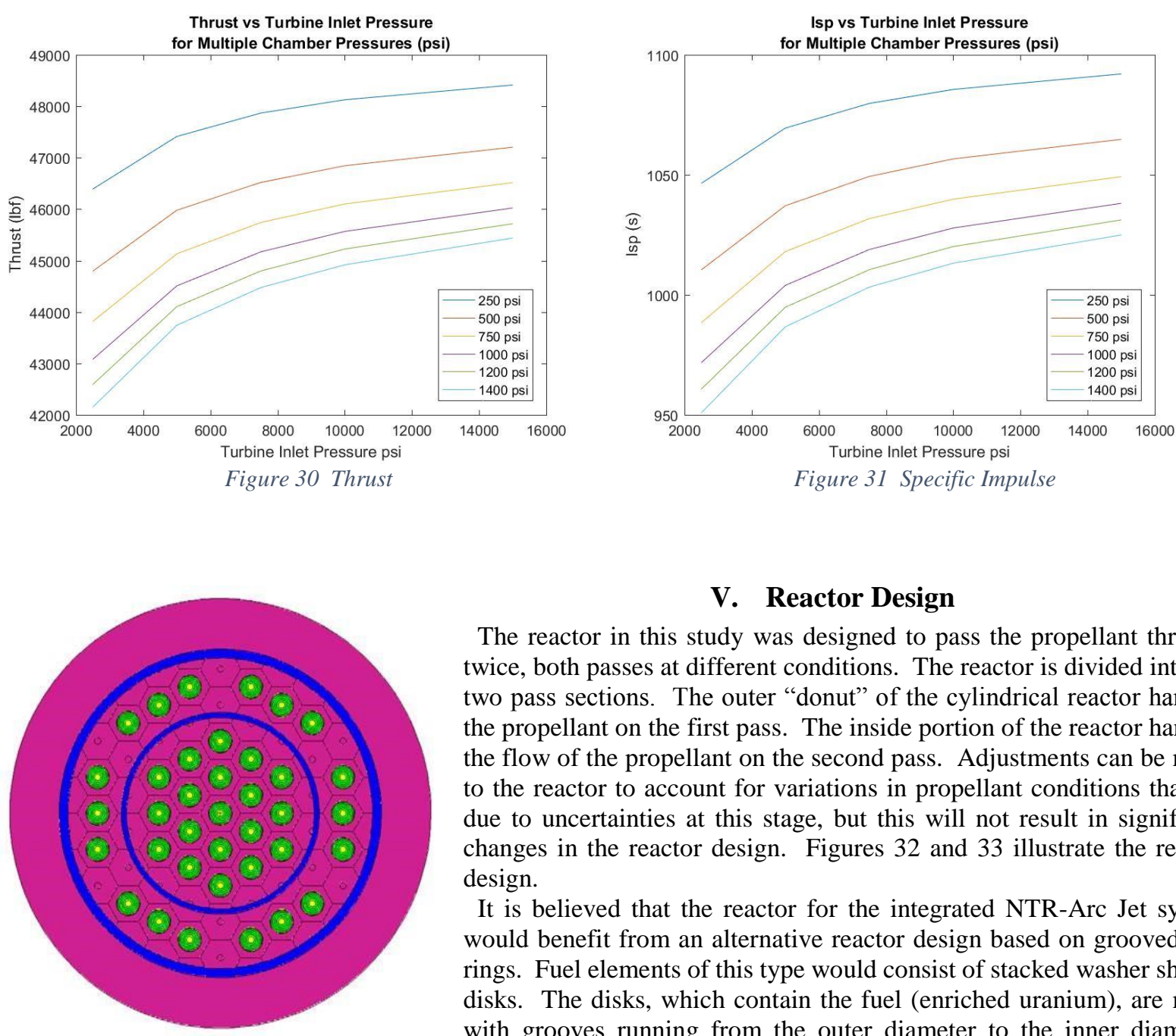

\section{Reactor Design}

The reactor in this study was designed to pass the propellant through twice, both passes at different conditions. The reactor is divided into the two pass sections. The outer "donut" of the cylindrical reactor handles the propellant on the first pass. The inside portion of the reactor handles the flow of the propellant on the second pass. Adjustments can be made to the reactor to account for variations in propellant conditions that are due to uncertainties at this stage, but this will not result in significant changes in the reactor design. Figures 32 and 33 illustrate the reactor design.

It is believed that the reactor for the integrated NTR-Arc Jet system would benefit from an alternative reactor design based on grooved fuel rings. Fuel elements of this type would consist of stacked washer shaped disks. The disks, which contain the fuel (enriched uranium), are made with grooves running from the outer diameter to the inner diameter.

Figure 32 Top View of Reactor Design

American Institute of Aeronautics and Astronautics 
When stacked they will form a cylindrical fuel rod. The grooves will allow propellant to flow from the outside of the cylinder to the inside of the fuel rings. This results in a large increase in surface area available for heat transfer. The increased heat transfer allows the propellant to be heated to temperatures beyond what can be reached in the traditional fuel rod in which flow travels down straight paths through hexagonal elements. This reactor design would decrease size and mass. The reduction in mass would raise the thrust to weight ratio and decrease the importance of one of the draw backs of this design. ${ }^{4}$

\section{Impact on Vehicle}

It is important, when designing propulsion systems, to consider the impact upon other vehicle systems. In a vehicle there are many interfaces and interactions between components and systems. The design of the engine will influence the entire vehicle to a large degree. Consequently, the engine design will, in part, determine

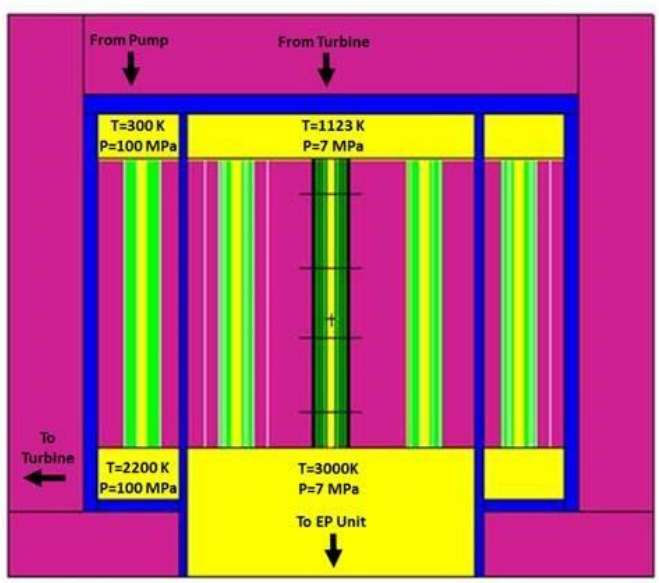

Figure 33 Side View of Reactor Design with Example Flow Conditions how the stage operates, mission capabilities of the vehicle, vehicle cost, etc. It is therefore prudent to discuss how this engine configuration impacts the vehicle differently than a standard NTR.

First of all, the multiple flow paths through the reactor and energy generation increase propulsion system complexity. This has consequences for reliability, redundancy, and verification of the propulsion system. These are import aspects to consider in an engine design. These issues will be driven partly by mission requirements, cost, and safety. This configuration also increases reactor complexity, which could impact reactor control and operation.

The next thing to consider is that this system operates best at high internal pressures. This is to allow for large expansion ratios across the turbine to generate the maximum amount of power for the arc jet. High internal pressure requires a strong pressure vessel, along with the lines and ducts, to contain the high operational pressure. The system will experience high pressure from pump outlet through the reactor first pass flow path to the turbine inlet. The pressure vessel will have to be built stronger for these components of the system. Furthermore, parts of the reactor are much lower in pressure, specifically the second pass flow path. The pressure differential between reactor components will require special design considerations when designing the fuel structure. The vessel needed to contain these high pressures will add weight to the system.

In addition to the added weight of the pressure vessel, this system will have increased mass compared to a standard NTR. The reactor will be larger to accommodate the two flow paths. The reactor will; therefore, be heavier. The addition of the generator and arc jet to the system, including the mounting and interface hardware, will also add weight to the system. Overall the configuration studied is expected have a higher thrust to weight ratio than an NTR.

Finally, waste heat must be considered. Efficiency limitations in the arc jet and generator/turbine power system result in a significant amount of waste heat. Several tens of megawatts must be managed. Some of this could be handled through the regenerative cooling system. This would reduce reactor power requirements a bit. Any heat the regenerative cooling system couldn't manage would have to be removed with radiators. Radiators for these power levels can become quite massive. They could potential impose a significant weight penalty. One can see that it is important to maximize efficiency and properly plan for waste heat management.

The factors discussed in this section are important considerations for this propulsion system. Ultimately a trade study will need to be conducted to weight the pros and cons of this system with the specific mission requirements that drive the need for high performance in mind.

\section{Conclusions}

In conclusion, there are both pros and cons to an integrated NTR-Arc Jet engine system. By integrating an arc jet into an NTR, the nuclear thermal reactor can be augmented by transferring additional energy to the propellant. The overall goal being to maximize energy deposited into the propellant prior to expanding it through a nozzle to generate thrust.

The NTR-Arc Jet integration raises the specific impulse of the standard NTR by several tens of seconds while maintaining high levels of thrust. The thrust in this system can be adjusted simply by increasing the mass flow rate and the energy output of the reactor. The exact increase in performance of this system depends upon advanced 
component technologies. Improvement in arc jet efficiency, or that of another electric propulsion device, as well as higher temperature limitations of turbines, significantly impact the increased performance of this system.

Downsides to the integrated augmented system include increased complexity, heavier pressure vessel, lower thrust to weight ratio, and radiators for waste heat. The advantages of this system would need to be traded with the disadvantages and compared to mission requirements in order to evaluate the suitability of the system. Mission requirements will determine if the potential benefits outweigh the disadvantages. In ambitious missions, in which the mission is sensitive to the specific impulse, this system may offer the best solution for obtaining the required propulsion system performance.

In addition to augmenting the propulsion system, a similar system could tap off some percent of the augmenting power for use in other vehicle systems. This could reduce the need for other power systems and perhaps save weight as well as result in additional benefits. This may be a concept of interest for certain missions and vehicles.

\section{Acknowledgments}

The authors would like to thank James Maddox, a graduate student at the University of Alabama, for his ideas, thoughts, and discussion of our complimentary engine analyses. The authors would also like to thank the Science Technology and Mission Directorate and the Center Innovation Fund for their support in this effort.

\section{References}

[1] E. Ito, K. Tskagoshi, J. Masada, K. Ishizaka, K. Saitoh and T. Torigoe, "Key Technologies for Ultra-High Temperature Gas Turbines," in Mitsubishi Heavy Industries Technical Review, 2015.

[2] S. Hada, K. Tsukagoshi, J. Masada and E. Ito, "Test Results of the World's First 1,600 C J-series Gas Turbine," in Mitsubishi Heavy Industries Technical Review, 2012.

[3] G. Sutton and O. Biblarz, Rocket Propulsion Elements, 8th ed.

[4] L. Barkett, W. Emrich, A. Mathias, J. Cassibry and T. Kim, "Multiphysics Modeling of a Single Channel ina Nuclear Thermal Propulsion Grooved Ring Fuel Element," in Proceedings of Nuclear and Emerging Technologies for Space, Albuquerque, NM, 2013.

[5] C. C. Dobson, T.-S. Wang, W. B. Clifton, J. Foote, R. J. Litchford and J. P. Foote, "Hyperthermal Environments Simulator for Nuclear Rocket Engine Development," in Proceedings of Nuclear and Emerging Technologies for Space, Albuquerque, NM, 2011.

American Institute of Aeronautics and Astronautics 